\title{
Inclusão: concepções dos docentes da Secretaria de Educação do Estado de São Paulo
}

\author{
Márcia Miranda Silveira Bello* \\ Universidade Estadual Paulista Júlio de Mesquita Filho \\ Vera Lúcia Messias Fialho Capellini** \\ Universidade Estadual Paulista Júlio de Mesquita Filho \\ Job Antonio Garcia Ribeiro*** \\ Universidade Federal do Triângulo Mineiro
}

Resumo Atualmente, respeitar as diferenças e promover a inclusão são temas frequentes nas mais variadas esferas, dentre elas a educacional. Nesse contexto, o termo inclusão tem assumido múltiplos enfoques originando diferentes práticas educacionais por quem objetiva concretizá-lo. $\mathrm{O}$ objetivo do presente trabalho foi analisar a compreensão que os docentes da Rede Estadual de Educação de São Paulo possuem desse conceito. Os dados foram coletados por meio de narrativas elaboradas pelos sujeitos durante um curso de formação continuada oferecido por meio do Programa Rede São Paulo de Formação Docente (REDEFOR). Os principais resultados apontam para a necessidade de se superar uma visão homogeneizante da educação que considera que apenas os alunos com deficiência são diferentes dos demais, e na qual a inclusão escolar se destinaria apenas a esse público.

PALAVRAS-CHAVE: REDEFOR; Formação continuada; Inclusão escolar. 
Inclusion: conceptions of teachers of the Secretariat of Education of the State of São Paulo

Abstract Recently, respecting differences and promoting inclusion are frequent topics in a wide range of research, including education. In this context, the term inclusion has assumed multiple approaches giving rise to different educational practices by those who intend to concretize it. The objective of the present work was to analyze the understanding that state teachers of education of São Paulo have about this concept. The data were collected through narratives elaborated by the subjects during a continuing training course offered through the Programa Rede São Paulo de Formação Docente (REDEFOR). The main results point to the need to overcome a homogenizing view of education, which considers that only the students with disabilities are different from the others, and in which school inclusion would only be for this public.

KEYWORDS: REDEFOR; Continuing education; School inclusion.

\section{Introdução}

Em consonância com a tendência mundial de aperfeiçoamento democrático, a sociedade brasileira tem dado especial atenção à exclusão social, buscando meios para diminuí-la e traçando caminhos que possibilitem a melhoria da qualidade de vida de toda a população (GLAT; PLETSCH; FONTES, 2007; MORAES; MARANHE, 2009; KASSAR, 2011). Atualmente, "respeitar a diversidade" e "promover a inclusão" são afirmativas presentes nos mais variados contextos e discursos, desde conversas informais até documentos legais relacionados aos direitos humanos, ao serviço social e à educação.

Embora a humanidade sempre tenha sido caracterizada pela pluralidade cultural, nota-se recentemente uma maior preocupação com essas questões, tanto no campo social (Inclusão Social) quanto no âmbito educativo (Educação Inclusiva). Os homens nunca se perceberam tão diversos como nos dias de hoje.

Para Cardoso (2010), a globalização dos meios de comunicação exerceu um importante papel para essa mudança de perspectiva do ser humano com relação ao seu semelhante. Por intermédio de meios como a TV e a internet, foi possível conhecer diferentes formas de viver, de compreender o mundo e de se relacionar com ele.

Soma-se a esse fato a intensificação dos Movimentos Sociais pelos direitos humanos, principalmente a partir da década de 1960 que, associados à recente percepção do outro, prepararam terreno para o surgimento de uma nova perspectiva que busca proporcionar oportunidades de inserção social a todas as pessoas, sem nenhuma distinção (MENDES, 2006). 
A Educação Inclusiva faz parte desse movimento maior de repercussão mundial, denominado de Inclusão Social. Este movimento busca garantir a equiparação de oportunidades para todos os indivíduos, incluindo aqueles que historicamente foram colocados à margem da sociedade devido às condições econômicas, culturais, raciais, físicas e/ou intelectuais. Apoiando-se na universalização dos direitos humanos, no respeito e na valorização da diversidade, a Inclusão Social, para se concretizar, demanda um conjunto de ações político-administrativas a partir de leis, decretos e normativas nas mais diversas áreas sociais, dentre as quais, a educacional (CAPELLINI, 2008; MORAES; MARANHE, 2009; CARDOSO, 2010).

É nesse contexto que temos a Educação Inclusiva, cuja proposta consiste em transformar o sistema educacional em um sistema inclusivo, por meio de ações que respeitem as diferenças e se pautem na democratização do conhecimento historicamente construído. Influenciada pelo lema "Escola para todos", busca oferecer condições de aprendizagem em um só contexto, bem como prover subsídios para que todo e qualquer aluno aprenda satisfatoriamente (OMOTTE, 2004; CAPELLINI, 2008).

Nesse sentido, ações educativas inclusivas não se limitam à matrícula de todos os alunos em um mesmo espaço escolar, tampouco à inserção dos alunos público-alvo da Educação Especial (EE) no ensino regular. A Educação Inclusiva refere-se, na realidade, a um conceito mais amplo que inclui o respeito às diferenças sociais, individuais, religiosas, culturais, raciais, políticas e de gênero (MANTOAN, 2001). É um movimento de ação política e pedagógica em defesa do direito de todos os estudantes, que conjuga igualdade e diferença como valores indissociáveis, bem como propõe mudanças culturais e estruturais para que todos os alunos tenham suas especificidades atendidas. Trata-se de uma nova forma de enxergar o lugar de todos dentro da escola (PACHECO; EGGERTSDÓTTIR; MARINÓSSON, 2007).

No entanto, ainda existem muitas dúvidas e múltiplos olhares com relação ao que de fato essa nova abordagem representa. A prática cotidiana em sala de aula em muito se distancia daquilo que se compreende por Educação Inclusiva. Ações concretas não têm acontecido com a mesma intensidade que os debates, as pesquisas e as modificações nos marcos legais (RODRIGUES; CAPELLINI, 2009; MANTOAN, 2001; MATURANA, 2016).

Uma das razões apontadas para isso diz respeito à falta de compreensão ou à compreensão inadequada que os professores possuem acerca do que significa inclusão e qual o papel docente dentro desse processo (MATURANA, 2016). Embora expressões e conceitos como "Inclusão Escolar", "Cultura Inclusiva" e "Educação Especial" sejam familiares a muitos profissionais, não necessariamente são utilizados de forma adequada, o que acaba por gerar estereótipos e posicionamentos não fundamentados. Uma vez que professores, diretores e demais agentes da comunidade escolar possuem funções essenciais na estrutura e no funcionamento do sistema educacional, suas opiniões e olhares podem fornecer subsídios relevantes para compreendermos como ações dessa natureza estão sendo concretizadas (SANT'ANA, 2005; RODRIGUES; CAPELLINI, 2009). 
Assim, consideramos que identificar as concepções de professores participantes de um curso de Especialização acerca da Educação Inclusiva pode ser fundamental para se traçar ações futuras no que se refere à elaboração de práticas concretas no contexto educativo, bem como em relação à própria formação continuada. O que, afinal, esses profissionais que estão atuando nas escolas públicas do Estado de São Paulo entendem sobre o tema Inclusão?

O presente artigo buscou compreender o quanto essas concepções aproximam-se ou se distanciam das definições apresentadas na legislação brasileira e nos principais referenciais teóricos. Foram selecionadas 97 narrativas elaboradas durante a iniciação do curso de Especialização em Educação Especial e Inclusiva ocorrido em 2014 e oferecido aos profissionais da Secretaria de Educação do Estado de São Paulo (SEE/SP) em parceria com Universidade Estadual Paulista "Júlio de Mesquita Filho" - Unesp, Câmpus de Bauru, por meio do Programa Rede São Paulo de Formação Docente (REDEFOR).

Esse programa, ofertado na modalidade de Educação a distância (EaD), disponibilizou no ano referido sete cursos na área de "Educação Especial e Inclusiva". No total foram oferecidas 1.600 vagas, das quais 1.000 foram destinadas aos gestores no curso de "Educação Especial e Inclusiva" (444 horas) e 600 direcionadas aos docentes nas seguintes especialidades: Deficiência Auditiva (DA), Deficiência Física (DF), Deficiência Intelectual (DI), Deficiência Visual (DV), Altas Habilidades/Superdotação (AHS) e Transtornos Globais do Desenvolvimento (TGD), com duração de 686 horas cada.

Cada curso foi organizado em 16 disciplinas, das quais nove faziam parte de um tronco comum a todas as áreas e as outras sete eram exclusivas de cada especialidade. Para efeito de análise, esse estudo considerou somente a primeira disciplina do tronco comum (D01 - Diversidade e Cultura Inclusiva), especificamente, a atividade de elaboração de uma narrativa, onde os docentes deveriam opinar a respeito de como a diversidade poderia ser contemplada nas ações do cotidiano da escola. Foi a partir desse material que os dados foram coletados e sistematizados.

\section{Educação inclusiva: histórico e marcos legais}

Embora comumente se localize a origem desse movimento na década de 1990, em função da Conferência Mundial sobre Educação para Todos ocorrida em Jomtien na Tailândia, não se pode desconsiderar que as sociedades humanas vêm se tornando progressivamente inclusivas ao longo dos séculos. Pautada nas noções de diversidade, igualdade e cidadania, mas, principalmente, pelas ideias da Inclusão Social, a Educação Inclusiva carrega muitos dos preceitos contidos na Declaração Universal dos Direitos Humanos de 1948 (CARDOSO, 2010).

Para o autor, essa Declaração apresenta um quadro laico de valores ético-políticos que possibilita instrumentalizar o diálogo universal, a fim de facilitar a convivência na diversidade. Nesse sentido, busca contribuir para a construção de uma cultura de respeito à dignidade humana em todos os indivíduos e em todas as circunstâncias. 
Espaço-temporalmente a Educação Inclusiva teve início nos Estados Unidos na década de 1980 ao se propor reformas educacionais que possibilitassem uma maior qualidade de ensino para todos os alunos, independentemente de suas características pessoais. A partir de então, acabou ganhando o mundo na década de 1990. Segundo Mendes (2006, p. 392), "[...] a reestruturação das escolas aumentou também a consciência e o respeito à diversidade, e produziu mudanças no papel da escola, que passou a responder melhor às necessidades de seus diferentes estudantes".

Essas mudanças ganharam força nas políticas educacionais de outros países a partir da já citada Conferência Mundial sobre Educação para Todos e, mais fortemente, após a Conferência Mundial sobre Necessidades Educacionais Especiais de 1994, na qual se produziu a Declaração de Salamanca. Os documentos originários desses encontros tornaram-se parâmetros para a construção da ideia de Educação Inclusiva e subsidiaram a formulação de leis e políticas públicas, inclusive brasileiras (UNESCO, 1994; KASSAR, 2011).

Embora atualmente se defenda uma educação que se opõe à escola excludente, que durante décadas tem dificultado o acesso das pessoas tidas como fora do padrão social de normalidade, até meados da década de 1960, por exemplo, a escolarização era privilégio de poucos. Os mais pobres não frequentavam a escola para se dedicar ao trabalho desde muito cedo e as crianças que apresentavam algum tipo de deficiência eram segregadas do convívio social e da escola, a princípio dentro de suas casas e, a seguir, em asilos, abrigos ou classes especiais (RODRIGUES; CAPELLINI; SANTOS, 2014).

Nesse sentido, a Declaração de Salamanca veio afirmar que "[...] o princípio fundamental da escola inclusiva é o de que todas as crianças deveriam aprender juntas, independentemente de quaisquer dificuldades ou diferenças que possam ter" (UNESCO, 1994, p. 6). Logo, a Educação Inclusiva "[...] cobre variadas tentativas de atender à diversidade total das necessidades educacionais dos alunos" (PACHECO; EGGERTSDÓTTIR; MARINÓSSON, 2007, p.14). Para Stainback e Stainback (1999, p. 21),

Em um sentido mais amplo, o ensino inclusivo é a prática da inclusão de todos - independente do seu talento, deficiência, origem socioeconômica ou origem cultural - em escolas ou salas de aula provedoras, onde todas as necessidades dos alunos são satisfeitas.

Nos dizeres de Mendes (2006, p. 393), “[...] passou-se a defender um único sistema educacional de qualidade para todos os alunos, com ou sem deficiência”, embora em muitos contextos a Educação Inclusiva seja compreendida como sinônimo de Educação Especial (EE). Essa falta de clareza entre essas duas terminologias pode se dar em função da própria história que marcou as primeiras propostas EE.

Como destacam Omotte (1999) e Kassar (2011), a Educação Especial nem sempre foi compreendida como é hoje, sob a perspectiva da Educação Inclusiva. Ela tem uma história particular que se iniciou a partir de um modelo clínico de deficiência, na qual os indivíduos eram segregados e excluídos do processo educativo escolar comum. 
$\mathrm{O}$ atendimento educacional direcionado às pessoas com deficiência foi construído separadamente da educação regular em Instituições Especializadas. A EE, como campo de atuação específico, compunha inicialmente um sistema paralelo, pois se acreditava que a separação entre alunos "normais" e "anormais" traria maior benefício para todos. Com isso, principalmente durante a primeira metade do século XX, surgiram as primeiras instituições privadas de atendimento especializado, como foi o caso da Associação de Pais e Amigos dos Excepcionais (APAE).

Num segundo momento, buscando integrar o público-alvo da EE à sociedade, surge o paradigma da normalização e da integração. Nessa concepção, pessoas com deficiência, transtornos globais do desenvolvimento e altas habilidades/superdotação passaram a ser inseridas no contexto escolar, integrados às atividades do ensino comum. Todavia, isso se constituiu em mais segregação, pois embora inseridos em um mesmo contexto ou espaço físico as modalidades de EE e de ensino regular continuavam indiferentes umas às outras. Havia classes especiais para alunos com deficiência e classes comuns para alunos sem deficiência (OMOTTE, 1999; 2004; KASSAR, 2011).

As bases legais que permitiram a superação desse paradigma integrativo em direção a uma perspectiva inclusiva tiveram origem, como dissemos, nos diversos encontros internacionais e nos documentos produzidos a partir deles. No Brasil essas diretrizes e orientações internacionais acabaram por influenciar particularmente a Política Nacional de Educação Especial de 1994 e a Lei de Diretrizes e Bases (BRASIL, 1996).

Embora essa primeira Política Nacional tenha sido criada no mesmo ano da Declaração de Salamanca ela continha, no entanto, um caráter mais informativo e se apoiava ainda no paradigma integracionista. Foi somente com a Política Nacional de Educação Especial de 2008 (BRASIL, 2008) que se buscou transpor a visão anterior de caráter substitutivo da EE ao ensino comum, bem como superar a ideia de se organizar espaços educacionais separados para alunos com deficiência. A partir desse documento se esclarece e se diferencia os objetivos e as finalidades da Educação Inclusiva e da Educação Especial nessa perspectiva.

A Inclusão é então considerada “[...] uma ação política, cultural, social e pedagógica, desencadeada em defesa do direito de todos os alunos de estarem juntos, aprendendo e participando, sem nenhum tipo de discriminação"(BRASIL, 2008, p.1). Já a EE é entendida como uma modalidade de ensino que perpassa todos os níveis de ensino, da educação infantil ao ensino superior, funcionando como um suporte para o ensino e a aprendizagem de alunos que apresentam alguma deficiência, transtorno global do desenvolvimento ou alta habilidade/superdotação.

A Educação Inclusiva surge, portanto, como um enfrentamento à histórica exclusão escolar de diversos grupos que durante décadas tiveram seu acesso à escola restrito ou negado por uma concepção de educação pautada na homogeneização do ensino e em padrões de normalidade. Refere-se à inserção dessas pessoas no processo educativo, garantindo não apenas seu acesso ao ambiente escolar, mas, na mesma pro- 
porção, a efetivação de sua aprendizagem. Dessa forma, ela não se restringe àqueles com alguma deficiência, mas se estende a todas as pessoas consideradas em suas singularidades, buscando garantir seu acesso e permanência. É a partir dela que atualmente se compreende a EE como um apoio à inclusão de seu público-alvo no ensino regular.

Compreender essa distinção é fundamental para nos posicionarmos a favor de uma "Cultura Inclusiva" dentro da escola, uma cultura de aceitação, respeito e garantia ao direito às diferenças. Afinal, a escola é que deve se adaptar de forma a se tornar acessível a todos os estudantes, sem distinção de características físicas, intelectuais, religiosas, culturais ou raciais. Cabe às instituições de ensino considerar as especificidades de cada estudante, visto que são as diferentes formas de aprender que enriquecem o processo educacional (MANTOAN, 2001; CAPELLINI, 2008).

\section{Metodologia}

As narrativas selecionadas para análise foram aquelas postadas no Ambiente Virtual de Aprendizagem (AVA) do curso no período de 12 de março a 04 de maio de 2014. A maioria delas foi anexada após 15 de março, data em que os cursistas tiveram um Encontro Presencial (EP) no qual foram apresentados os primeiros aspectos e conceitos que fariam parte da disciplina D01 - Diversidade e Cultura Inclusiva.

Devido à amplitude do Curso de Especialização, foi realizado um recorte amostral do grupo de participantes que optou pela especialidade Altas Habilidades/ Superdotação (AH/S). Foram assim consideradas três turmas, cada qual com uma média de 32 profissionais. Haja vista que as vagas nos cursos voltados para as áreas da EE foram destinadas aos professores, apenas docentes que estavam atuando em escolas do Estado de São Paulo fizeram parte desta pesquisa. No total adotamos como objeto de análise 97 narrativas, nas quais os cursistas registraram suas opiniões em relação a como a diversidade poderia ser contemplada nas ações cotidianas escolares. Vale destacar que todos os envolvidos na pesquisa concordaram em participar desse estudo por meio de termo de consentimento livre e esclarecido.

As narrativas foram categorizadas à luz da teoria da Análise de Conteúdo proposta por Laurence Bardin (2009), considerada por Chizzotti (2006) como uma das diversas modalidades de interpretação de texto que busca extrair significados expressos ou latentes. Baseada na inferência, isto é, na dedução de maneira lógica, a Análise de Conteúdo pressupõe que um texto contém sentidos e significados que podem ser apreendidos por um leitor, o qual interpreta a mensagem escrita por meio de técnicas sistemáticas apropriadas, dentre as quais o estabelecimento de categorias (CHIZZOTTI, 2006). Refere-se a um "esforço de interpretação", que busca compreender as comunicações além dos seus significados imediatos, a partir de três fases:

(1a) Pré-análise: onde há a escolha dos documentos a serem analisados, bem como uma leitura flutuante e a formulação de hipótese na elaboração de indicadores que fundamentem a interpretação final. 
(2a) Exploração do material: onde ocorre seu tratamento para posterior codificação, juntamente com o estabelecimento de categorias, nas quais se condensam determinados significados a partir de unidades vocabulares ("método taxonômico"). Trata-se de uma operação de classificação de elementos, primeiramente por diferenciação (inventário) e depois por agrupamento (em função das características comuns dos elementos).

(3a) Tratamento dos dados, inferência e interpretação: após a codificação parte-se para a inferência, na qual se deduz de maneira lógica conhecimentos sobre o emissor da mensagem ou sobre seu meio. Refere-se ao procedimento intermediário que permite a passagem da descrição dos dados para a interpretação, ou seja, para a real significação do conteúdo, que se fundamentam impressões e juízos intuitivos por meio de operações conducentes a resultados de confiança (BARDIN, 2009).

Os dados foram analisados de forma a se estabelecer relações com a bibliografia consultada e, a partir de termos chave como "cultura inclusiva", "diversidade", "educação inclusiva" e "escola inclusiva", emergiram duas categorias relacionadas à ideia de Inclusão: (1) inclusão como um processo amplo que envolve toda a sociedade, categoria que se aproxima da ideia de Inclusão Social - IS; e (2) inclusão como um processo restrito ao ambiente escolar, que se refere ao acesso dos alunos à escola e aos conhecimentos escolares, ou seja, como sinônimo de Inclusão Escolar - IE. Nessa última categoria, foi possível observar ainda mais duas subcategorias relacionadas ao público alvo, cada uma delas ilustrada por um exemplar das narrativas a seguir:

- (2.1) Inclusão como um processo de acesso à educação escolar por alguns alunos considerados "fora do padrão de normalidade".

As diversidades podem ser contempladas através de atividades de sala preparadas para atender aos alunos especiais, adaptação do espaço físico da unidade escolar, na busca do respeito com o próximo, entre outras. [...] A escola pode criar um ambiente de cultura inclusiva através de iniciativa da busca do respeito entre os alunos, campanhas educativas informando sobre as deficiências, entre outras (Narrativa 1, Turma 2).

- (2.2) Inclusão como um processo de acesso à educação escolar por toda e qualquer pessoa.

Promover a diversidade na escola é trabalhar com cada aluno dentro de suas limitações e possibilidades em busca de situações que promovam a melhoria na vida escolar e social, como um todo, de crianças e adolescentes, sejam eles alunos deficientes ou não. A verdadeira inclusão trabalha com todos (Narrativa 32, Turma 1).

Das 97 narrativas, duas não se encaixaram em nenhuma categoria por apresentar definições vagas que não nos permitiram extrair a concepção de inclusão adotada pelos docentes que as escreveram.

Para a análise das concepções tomamos como base as definições dos termos "Inclusão Social", "Educação Inclusiva" e "Educação Especial" apresentadas por documentos oficiais do MEC e pela legislação brasileira, bem como, as definições pre- 
sentes na literatura (autores nacionais e internacionais citados anteriormente). Dessa forma, procuramos verificar a proximidade das respostas apresentadas pelos sujeitos a essas definições tomadas como parâmetros, tal como no estudo realizado por Sant'ana (2005). Essas análises partiram da ideia de que tanto os autores indicados quanto os marcos legais, consideram que a inclusão é um processo amplo de inserção social de grupos historicamente excluídos da sociedade. Nesse sentido, as concepções que se distanciam dessa prerrogativa podem ser consideradas incompletas ou mesmo inadequadas.

\section{Apresentação e discussão dos resultados}

Das 97 narrativas em que analisamos a compreensão que os docentes da Rede Estadual de Educação de São Paulo tinham sobre inclusão, foi possível observar que $28 \%$ ou 27 educadores, a relacionaram com a ideia de Inclusão Social (categoria 1). Já 68 narrativas, cerca de 70\%, relacionaram esse termo com a ideia de Inclusão Escolar (categoria 2), (Gráfico 1). Cabe relembrar ainda que, em duas narrativas não foi possível extrair a compreensão de inclusão adotada por seus autores, o que corresponde a $2 \%$ do total de trabalhos analisados.

Gráfico 1: Concepção dos sujeitos sobre o termo Inclusão

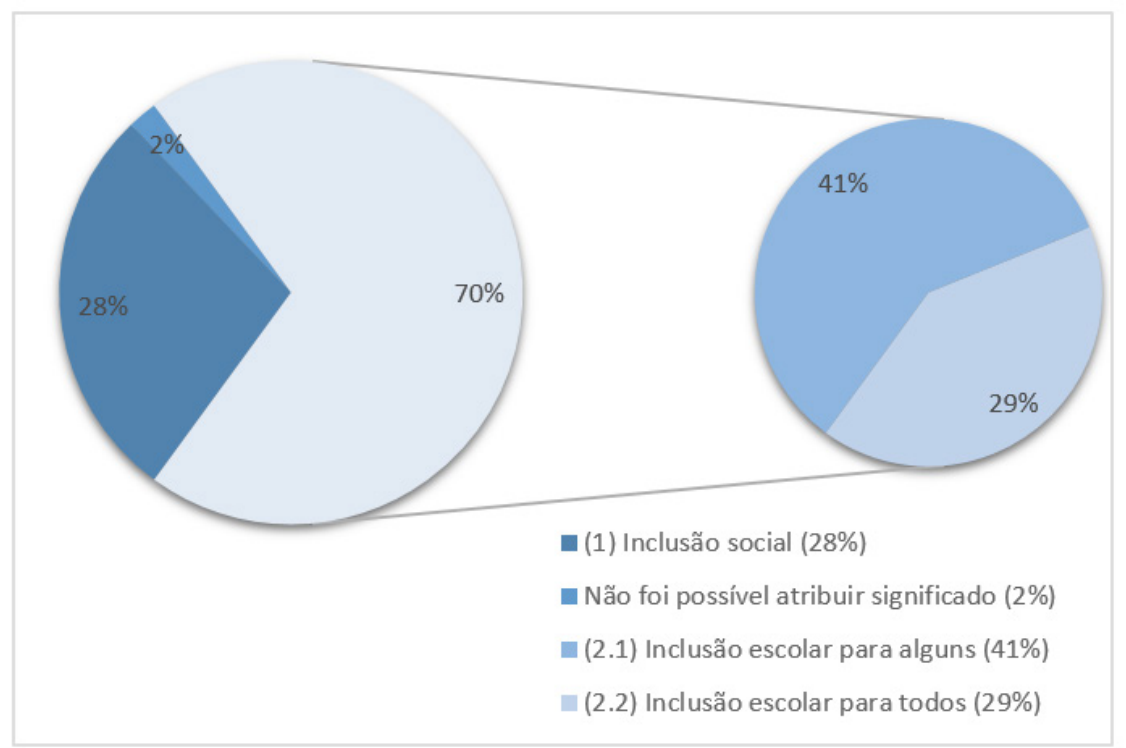

Fonte: elaborado pelos autores 
A categoria 1 contemplou afirmações que valorizavam as diferenças, que compreendiam cada ser humano como único, que evidenciavam a importância do respeito pelo próximo e a necessidade de superação do preconceito. Já na categoria 2 foram inseridas narrativas que diziam respeito à inclusão e faziam clara menção ao ambiente escolar, contemplando expressões como: "dentro da escola", "no aprendizado" ou "no ambiente escolar".

A razão da maioria das narrativas relacionar a inclusão ao contexto escolar pode ser explicada pelo fato de que os dados foram coletados em um curso de formação continuada de professores cuja temática era "Educação Especial e Inclusiva". Esse assunto, aliado ao público alvo do curso, reforça a ideia de que durante as aulas os temas abordados seriam referentes à escola.

Outro aspecto relevante é que dentre as 68 narrativas da categoria 2, 40 profissionais, ou seja 41\%, ainda atribui à inclusão o significado de acesso à educação por alguns alunos (subcategoria 2.1). Uma fala muito comum nessas narrativas é a de que apenas alguns estudantes são diferentes. Há, por exemplo, expressões como: "outras diversidades", "aquele aluno que é estranho ou peculiar", ou "aquele aluno que apresenta limitações e dificuldades", como se todos os demais alunos fossem iguais entre si.

Contudo, apenas 28 delas (29\%) consideram que a inclusão deva ser para todos os alunos (subcategoria 2.2). Nessa subcategoria se sobressaíram afirmações que apontavam as diferenças individuais como propulsoras da aprendizagem ou que as diferenças individuais deveriam ser respeitadas dentro da escola, desconsiderando o contexto mais amplo no qual as pessoas estão inseridas.

Podemos considerar que do percentual total das narrativas analisadas, cerca de $41 \%$ dos cursistas que fizeram parte da amostra ainda tem uma concepção sobre inclusão muito distante daquela considerada adequada de acordo com referenciais adotados nesse trabalho. Embora não se trate da maioria, ainda é um número bastante significativo quando se considera o impacto que as concepções educacionais dos profissionais da área têm sobre suas ações.

É fundamental salientar ainda que dentre a fala desses 40 educadores está muito forte a ideia de que a inclusão se restringe ao público alvo da Educação Especial, como podemos observar no exemplo abaixo:

Sem ser uma ação assistencialista, a educação inclusiva, procura, de forma humanista e democrática, a inserção da criança com necessidades educativas especiais na educação escolar regular, com o objetivo de propiciar a interação, nem sempre fácil, entre ela e as demais crianças (Narrativa 14, Turma 3).

Essa ideia corresponde a maioria das narrativas de professores que acreditam que a inclusão se limita a alguns alunos. Das 40 narrativas que se encaixam na Categoria 2.1, 30 compreendem que a IE é sinônimo de inserção dos alunos com deficiência na escola regular, enquanto outros 10 acreditam que ela deva ser direcionada não apenas para alunos com alguma deficiência, mas também a alunos com dificuldade 
de aprendizagem ou comportamento. Consideramos que a própria amostra do trabatho (sujeitos que optaram pela especialidade Altas Habilidades/Superdotação) tenha influenciado essas respostas (Tabela 1).

Tabela 1: Concepção dos sujeitos sobre o público alvo da Inclusão Escolar (Categoria 2)

\begin{tabular}{|c|l|c|}
\hline Subcategorias & \multicolumn{1}{|c|}{ Definição } & $\begin{array}{c}\text { Números } \\
\text { absolutos }\end{array}$ \\
\hline \multirow{2}{*}{$\begin{array}{c}\text { 2.1 Inclusão escolar } \\
\text { para alguns }\end{array}$} & $\begin{array}{l}\text { Apenas alunos com alguma deficiência } \\
\text { dificuldade de aprendizagem e/ou de } \\
\text { comportamento e alunos com deficiência) }\end{array}$ & 30 \\
\hline $\begin{array}{c}\text { 2.2 Inclusão escolar } \\
\text { para todos }\end{array}$ & Todos os alunos & 28 \\
\hline \begin{tabular}{c} 
Total de narrativas referentes à Categoria 2 \\
\multicolumn{2}{|c|}{}
\end{tabular} & 68 \\
\hline
\end{tabular}

Fonte: elaborado pelos autores

Algumas narrativas têm início com uma pequena explanação sobre a inclusão como um direito de todos, porém terminam exemplificando a inclusão dentro da escola com ações voltadas às pessoas com deficiência. Essas explanações parecem demonstrar que muitos professores estão reproduzindo um discurso "socialmente aceito", embora não tenham se apropriado dele concretamente.

Essa limitação da compreensão da educação inclusiva como sendo apenas o acesso do aluno com deficiência ao ambiente escolar também está presente no trabalho de Sant'ana (2005), que verificou que a maioria dos professores por ela entrevistados relaciona educação inclusiva às crianças com deficiência.

Um pequeno número de sujeitos considera ainda que o fato dos alunos com deficiência estarem sendo matriculados com mais frequência na escola regular em comparação ao que ocorria a alguns anos atrás, significa que exista inclusão. A narrativa a seguir é o exemplo de um discurso comum entre esses educadores: "A diversidade e a cultura inclusiva já 'é' (sic) realidade nas escolas tanto públicas como privadas, pois as salas para alunos especiais foram extintas há muito tempo" (Narrativa 31, Turma 1).

Contudo os estudos levantados por Silveira, Enumo e Rosa (2012) apontam que na prática os alunos com alguma deficiência não são atendidos adequadamente em suas necessidades dentro da escola, o fato de estarem matriculados em uma escola regular não garante que estejam incluídos no processo de ensino-aprendizagem.

É pertinente considerar que a maioria das narrativas não foi escrita sem consulta prévia a materiais que tratavam do tema, como foi orientado. Dentre as 97 
narrativas analisadas, 69 foram escritas após o primeiro Encontro Presencial (EP) e depois dos alunos terem tido acesso aos materiais de estudo no AVA, o que proporcionaria aos cursistas, ao menos em tese, o contato com os conceitos adotados pela literatura e pela legislação (Tabela 2).

Tabela 2: Concepção dos sujeitos sobre o termo Inclusão antes e depois do encontro presencial

\begin{tabular}{|c|c|c|c|}
\hline Categorias & $\begin{array}{c}\text { Narrativas } \\
\text { escritas antes } \\
\text { do EP }\end{array}$ & $\begin{array}{c}\text { Narrativas } \\
\text { escritas depois } \\
\text { do EP }\end{array}$ & $\begin{array}{c}\text { Total de } \\
\text { narrativas por } \\
\text { categoria }\end{array}$ \\
\hline 1 Inclusão Social & 8 & 19 & 27 \\
\hline $\begin{array}{c}\text { 2.1 Inclusão escolar para } \\
\text { alguns }\end{array}$ & 12 & 28 & 40 \\
\hline 2.2 Inclusão escolar para \\
todos
\end{tabular}

Fonte: elaborado pelos autores

Era de se esperar que dentre essas narrativas houvesse um número menos significativo de profissionais que associassem a ideia de inclusão apenas à pessoa com deficiência, o que não ocorreu. $31 \%$ dos cursistas que escreveram a narrativa após o EP ainda afirmavam que a inclusão escolar se restringia ao acesso de alguns alunos à escola regular, mais frequentemente relacionando esses "alguns" aos alunos com deficiência (Gráfico 2). 
Gráfico 2: Concepção dos sujeitos sobre o termo Inclusão antes e depois do encontro presencial em porcentagem

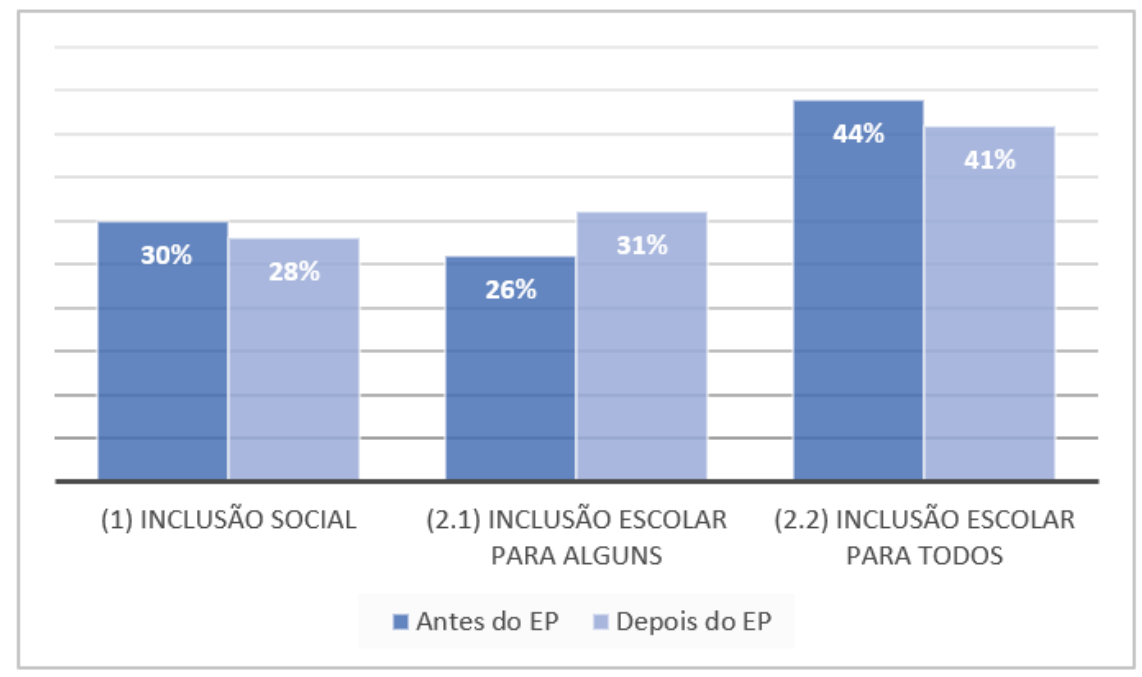

Fonte: elaborado pelos autores

Tanto nos trabalhos analisados por Maturana (2016) e Silveira, Enumo e Rosa (2012) quanto na pesquisa realizada por Sant'ana (2005) fica evidenciada a importância da formação do professor como uma ação que promova a efetivação das políticas inclusivas. Nesse sentido, havia também a expectativa de que a maioria dos professores que escreveram a narrativa após o EP apresentasse ideias mais próximas daquelas defendidas pelos materiais adotados, ou seja, tivesse maior clareza da dimensão da Inclusão como uma ação política e pedagógica de respeito à diversidade presente em todos os aspectos da vida social. Entretanto, apenas $28 \%$ se mostraram coerentes com essa concepção.

Podemos observar que o EP e as supostas leituras dos materiais da disciplina sobre "Cultura inclusiva e Diversidade" influenciaram muito pouco as concepções dos professores, visto que a porcentagem de respostas em cada categoria é muito próxima (Gráfico 2). Gatti (2003) nos explica que na formação continuada docente, oferecer informações e conteúdos nem sempre é suficiente para provocar mudanças na forma de pensar e no domínio de novos conhecimentos. Isso porque o professor é um ser social inserido em uma cultura, pertencente a grupos sociais que tem suas referências sobre valores, modos de ser e agir.

Para Matos e Mendes (2014), no caso da Inclusão Escolar a determinação em vencer desafios, a busca por práticas sociais inclusivas e a busca por uma educação para a diversidade são atitudes não apenas resultantes dos saberes adquiridos no meio acadêmico, mas também de "[...] sensibilidade e de experiências de vida que promovem maior criticidade em relação ao problema da exclusão, mobilizando algum tipo 
de busca pela transformação de si mesmo, de suas práticas pedagógicas e da escola” (MATOS; MENDES, 2014, p.50).

Assim, a formação não pode se restringir à participação em cursos eventuais, é necessário fornecer subsídios aos profissionais da educação para que possam refletir sobre suas práticas, compreender suas crenças e se tornarem pesquisadores de suas ações, buscando aprimoramentos e reconstruções (SANT'ANA, 2005).

\section{Considerações finais}

O estudo buscou analisar o quanto as concepções sobre inclusão apresentadas por alguns docentes da Rede Estadual de Educação de São Paulo aproximavam-se dos referencias teóricos adotados, os quais afirmam que a inclusão é uma ação política e pedagógica em favor da inserção social daqueles historicamente excluídos por serem considerados desviantes de um padrão social.

Os principais resultados demonstram que os docentes ainda estão bastante divididos entre aqueles que já compreendem a inclusão como um processo amplo de participação social e aqueles que restringem a inclusão ao ambiente escolar.

O dado que merece maior destaque é o do número elevado de professores que consideram que a inclusão se restringe ao acesso do aluno com deficiência ao ambiente escolar, evidenciando que a visão homogeneizante que durante séculos tem permeado as práticas escolares ainda não foi superada. $O$ professor que apresenta essa concepção desconsidera as diferenças individuais de cada aluno, os vê como uma massa de pessoas iguais, na qual os alunos com deficiência se sobressaem por serem os únicos "diferentes".

Embora reconheçamos que esses dados poderiam ser diferentes se comparássemos as respostas dos professores no início do curso com aquelas dadas ao final, já que os docentes teriam mais tempo para se apropriarem desses conceitos, eles reforçam a necessidade de reflexões intensas e constantes sobre a escola que temos e sobre aquela que queremos construir.

\section{Referências}

BARDIN, L. Análise de Conteúdo. 4. ed. Lisboa, Portugal: Edições 70, 2009.

BRASIL. Ministério da Educação e Cultura. Lei de Diretrizes e Bases de Educação Nacional - Lei No 9394/96. Brasília, 1996.

BRASIL, Ministério da Educação. Secretaria de Educação Especial. Política Nacional de Educação Especial na Perspectiva da Educação Inclusiva. Brasília: MEC/SEESP, 2008.

CAPELLINI, V. L. M. F. Práticas em educação especial e inclusiva na área da deficiência mental. Bauru: MEC/FC/SEE, 2008.

CARDOSO, C.M. Fundamentos para uma educação na diversidade. In: CAPELLINI, V.L.M.F.; RODRIGUES, O.M.P.R.; SANTOS, D.A.N. (Orgs.) Diversidade e cultura inclusiva, 2010, p.10-30 [E-book]. Disponível em: <http://www.acervodigital.unesp.br/bitstream/ unesp/155241/3/unesp-nead_reei1_ei_d01_e-book.pdf>. Acesso em: 23 jun. 2015. 
CHIZZOTTI, A. Pesquisa qualitativa em ciências humanas e sociais. Petrópolis, RJ: Vozes, 2006.

GATTI, B. A. Formação Continuada de Professores: A questão psicossocial. Cadernos de Pesquisa, n. 119, p. 191-204, jul., 2003.

GLAT, R.; PLETSCH, M. D.; FONTES, R. de S. F. Educação inclusiva \& educação especial: propostas que se complementam no contexto da escola aberta à diversidade. Educação, Santa Maria, v. 32, n. 2, p. 343-356, jul./dez., 2007. Disponível em: <https://periodicos.ufsm.br/reveducacao/article/view/678>. Acesso em: 04 out. 2016.

KASSAR, M. C. M. Educação especial na perspectiva da educação inclusiva: desafios da implantação de uma política nacional. Educar em Revista, Curitiba, n. 41, p. 61-79, jul./set., 2011. Disponível em: <http://www.scielo.br/pdf/er/n41/05.pdf>. Acesso em: 26 mai. 2016.

MANTOAN, M. T. E. Todas as crianças são bem-vindas à escola. Revista Profissão Docente, Uberaba, v.1, n.2, p.1-19, mai./ago., 2001. Disponível em: < http://www.revistas.uniube.br/index. $\mathrm{php} / \mathrm{rpd} /$ article/view/32/515>. Acesso em: 19 set. 2016.

MATOS, S. N.; MENDES, E. G. A proposta de inclusão escolar no contexto nacional de implementação das políticas educacionais. Práxis Educacional, Vitória da Conquista, v. 10, n. 16 p. 35-59, jan./jun. 2014. Disponível em: <http://periodicos.uesb.br/index.php/praxis/article/ viewFile/2889/2571>. Acesso em: 29 nov. 2016.

MATURANA, A.P.P.M. Transferência e alunos com deficiência intelectual das escolas especiais às escolas comuns sob diferentes perspectivas. São Carlos. 2016. $208 \mathrm{f}$. Tese (Doutorado em Educação Especial)-Universidade Federal de São Carlos, São Carlos, 2016.

MENDES, E. G. A radicalização do debate sobre inclusão escolar no Brasil. Revista Brasileira de Educação, v. 11, n. 33, set./dez. 2006. Disponível em: <http://www.scielo.br/pdf/rbedu/ v11n33/a02v1133.pdf >. Acesso em: 25 jul. 2016.

MORAES, M. S. S.; MARANHE, E. A. (Orgs.). Introdução Conceitual para Educação na Diversidade e Cidadania. São Paulo: UNESP/Pró-Reitoria de Extensão/Faculdade de Ciências, 2009. V.2, Coleção UNESP/CECAD-UAB.

OMOTE, S. Normalização, integração, inclusão. Revista Ponto de Vista, v.1, n., p. 4-12, 1999.

OMOTE, S. Estigma no tempo da inclusão. Revista Brasileira de Educação Especial, Marília, v.10, n.3, p.287-308, set.-dez. 2004.

PACHECO, J.; EGGERTSDÓTTIR, R.; MARINÓSSON, G.L. Caminhos para a inclusão: um guia para o aprimoramento da equipe escolar. Porto Alegre: Artmed, 2007.

RODRIGUES, O. M. P. R.; CAPELLINI,V.L.M.F. Concepções de professores acerca dos fatores que dificultam o processo da Educação Inclusiva. Educação, Porto Alegre, v. 32, p. 355$364,2009$.

RODRIGUES, O. M. P. R.; CAPELLINI, V. L. M. F.; SANTOS, D. A. N. dos. (Orgs.). Diversidade e Cultura Inclusiva. Bauru, SP: UNESP/Programa Rede São Paulo de Formação Docente (Redefor), 2014.

SANT'ANA, I. M. Educação Inclusiva: concepções de professores e diretores. Psicologia em Estudo, Maringá, v. 10, n. 2, p. 227-234, mai./ago. 2005. Disponível em: <http://www.scielo.br/ pdf/pe/v10n2/v10n2a09.pdf>. Acesso em: 30 nov. 2016.

SILVEIRA, K. A.; ENUMO, S. R. F.; ROSA, E. M. Concepções de professores sobre inclusão escolar e interações em ambiente inclusivo: uma revisão da literatura. Revista Brasileira de Educação Especial, Marília, v. 18, n. 4, p. 695-708, out./dez., 2012.

STAINBACK, S.; STAINBACK, W. Inclusão: Um guia para educadores. Tradução de Magda França Lopes. Porto Alegre: Artmed, 1999.

UNESCO. Declaração de Salamanca e linha de ação sobre necessidades educativas especiais. Brasília: UNESCO, 1994. 
Márcia Miranda Silveira Bello - Vera Lúcia Messias Fialho Capellini - Job Antonio Garcia

Ribeiro

* Mestre em Docência para a Educação Básica pela Universidade Estadual Paulista, Júlio de Mesquita Filho, Bauru, São Paulo, Brasil.

** Professora doutora da Universidade Estadual Paulista Júlio de Mesquita Filho, Bauru, São Paulo, Brasil.

*** Professor doutor da Universidade Federal do Triângulo Mineiro, Iturama, Minas Gerais, Brasil.

\section{Correspondência}

Vera Lúcia Messias Fialho Capellini - Universidade Estadual Paulista Júlio de Mesquita Filho, Departamento de Educação, Faculdade de Ciências de Bauru. Av. Eng. Luiz Edmundo Carrijo Coube, 14-01. CEP: 17033-360. Bauru, São Paulo, Brasil.

E-mail:marciamsbello@gmail.com - verinha@fc.unesp.br - job.ribeiro@uftm.edu.br

Recebido em 28 de março de 2017

Aprovado em 13 de setembro de 2017 